\title{
Ciencias de la documentación, patrimonio cultural y revolución digital: definiendo el futuro más allá de la tecnología
}

\author{
Francisco Javier García Marco \\ Universidad de Zaragoza (España)
}

\section{Resumen}

Se exploran las relaciones entre ciencias de la documentación y patrimonio cultural en el contexto de la revolución digital, una relación que va más allá del carácter instrumental que la documentación posee para las diferentes disciplinas, ya que la actividad documental tiene su raíz más profunda en la necesidad de preservar y hacer accesible el patrimonio cultural de los grupos, las instituciones y las sociedades en sus diferentes aspectos. Conforme los contenidos técnicos de la gestión, el tratamiento y la recuperación de la información van quedando progresivamente a cargo de los tecnólogos, y, especialmente, de los informáticos, el entronque de las ciencias de la documentación con la preservación del patrimonio cultural, especialmente a través del concepto de memoria social, se está convirtiendo en una de las claves de futuro para la disciplina.

Palabras clave: Ciencias de la documentación. Patrimonio cultural. Relaciones interdisciplinares. Internet.

\section{Abstract}

The disciplinary relations between Information Science and cultural heritage are explored in the context of the digital revolution. This relation goes beyond the instrumental character that Information Science has for almost any other discipline, as the very purpose of documentation is to preserve and make accessible the cultural heritage in its different aspects. As the technical aspects of information management, processing and retrieval are absorbed by the technologists, specially by the computer scientists, the core reference of Information Science to the non-material aspects of cultural heritage -including scientific heritage - is becoming one of the rising stars in the horizon of the discipline, specially around the concept of social memory. 
Keywords: Information Science. Documentation. Cultural heritage. Interdisciplinary relations. Internet.

La relación entre ciencias de la documentación y patrimonio cultural siempre ha sido intensa. Las instituciones documentales - archivos, bibliotecas y museos - surgieron como una actividad ligada a la preservación de documentos, conocimientos y objetos de alto valor cultural para las instituciones que tenían interés en ellos y capacidad para asumirla.

Con la expansión del conocimiento académico que aconteció en la época helenística, la biblioteca cuajó y despegó como una institución especializada en la preservación y el acceso al conocimiento filosófico y literario. Más tarde, con la explosión y especialización del conocimiento científico que se produjo tras el Renacimiento, la preservación de este conocimiento se convirtió en el nuevo frente de crecimiento de estas disciplinas, aunque también se desarrolló extraordinariamente la colección de libros y objetos de arte. En los dos últimos siglos, la extensión del concepto de cultura a todos los aspectos de la vida material e inmaterial de las comunidades humanas amplió extraordinariamente el ámbito de la documentación. Finalmente, en nuestros tiempos, las tecnologías del audio y el vídeo digital han llevado a cotas aún más altas la documentación y preservación de los testimonios de la vida cotidiana, económica, social y política, no solo de la "cultural", un concepto, por otra parte, cada vez más desdibujado.

Se puede afirmar, por tanto, que la documentación surge y se desarrolla al servicio de la preservación del patrimonio cultural en un sentido amplio, por más que, en distintas épocas y por distintos sectores, se haya situado el énfasis en una parte u otra de dicho patrimonio. No es anecdótico al respecto - antes bien, es muy significativo-, que durante siglos y aun en la actualidad a estos profesionales se les haya dado el nombre de curadores (curators en inglés) y otros parecidos.

Sin embargo, durante las últimas décadas, la revolución de las tecnologías de la información y la comunicación, por su carácter infraestructural respecto a la actividad informativa documental, ha desplazado el énfasis dentro de las ciencias de la documentación desde la antigua perspectiva culturológica a otra de carácter marcadamente tecnológico. Durante las etapas iniciales de este periodo, la documentación se entroncó con las tecnologías y devino en Information Science, ciencia de la representación, recuperación, transferencia y uso de la información almacenada. La Information Science se definió durante sus primeros años como una suerte de ciencia compañera de la Computer Science. En este proyecto de división del trabajo, a la primera le correspondía ocuparse de facilitar la transferencia social del conocimiento almacenado en bases de datos - la "informa- 
ción” - utilizando la infraestructura tecnológica desarrollada por la segunda, así como un conjunto de procedimientos informacionales desarrollados de forma alternativa - y complementaria - a la Library Science en los que ha basado su prestigio social y científico hasta la actualidad.

Sin embargo, las cosas no han resultado tan sencillas, en gran parte por el extraordinario auge que ha tenido el complejo científico-industrial de los ordenadores y las comunicaciones. Explotando sus posibilidades reales de aplicación práctica, la informática amplió muy pronto su primitivo foco de interés en el cálculo masivo de datos - la computación - a la producción de documentos y la gestión de información - mucho más ubicua y, por tanto, susceptible de ampliar notablemente su mercado- - Al final del periodo, la informática confluyó con las telecomunicaciones en un nuevo ciclo de cambio tecnológico en el cual todavía estamos imbuidos.

Como resultado de todo este proceso y como muestra muy bien el ejemplo de Google o Yahoo, la Computer Science -informática o información automática en el idioma español - ha terminado absorbiendo gran parte del ámbito estrictamente técnico de la Information Science. Esta está quedando en los últimos años progresivamente relegada a la frontera entre los sistemas tecnológicos y los aspectos sociales, psicológicos y comunicacionales que aún no han sido totalmente incorporados a sus modelos, o, si se quiere, que aún no han sido totalmente automatizados. No se debe olvidar, además, que, desde el proyecto de la inteligencia artificial, la informática ha convertido la formalización del conocimiento y de la transferencia de la información en el centro de su misión disciplinar - una referencia más reciente es el magno proyecto de la Web Semántica-; y, conforme la investigación extiende el alcance de los formalismos de representación y organización del conocimiento, estos quedan ligados a su núcleo científico.

Esta pretensión teórica no tendría mayor importancia - es frecuente que los objetos de investigación se compartan, por ejemplo, en las ciencias sociales - si no fuera acompañada de un poder económico mucho mayor que el de cualquiera de las disciplinas que compiten por su objeto de conocimiento. Ciertamente, la informática es una de las principales industrias de nuestro tiempo y todos los aspectos relacionados con la recuperación y organización de la información en medios digitales - los principales, por otra parte - se han convertido en frentes de investigación empresariales, en los que la universidad juega un papel importantísimo, pero subsidiario. Ante ella, el mundo de las unidades y servicios de información tienen una importancia económica mucho más pequeña. De igual manera, la informática ha configurado un cuerpo profesional muy amplio, progresivamente más corporativo, y ha desarrollado una presencia académica crecientemente proporcional a su dimensión industrial. 
Como consecuencia de las enormes diferencias de potencial, campos enteros de la teoría informativo-documental de hace algunos años están siendo absorbidos por el mundo de la tecnología informática y eso se nota, como no podía ser de otra manera, en la terminología. Así, los formatos de descripción han devenido en esquemas de metadatos, la catalogación en asignación de metadatos, los lenguajes documentales se están convirtiendo en ontologías orientadas a la recuperación de información, y la World Wide Web se concibe en el proyecto de la Web Semántica como una biblioteca digital universal. En definitiva, conceptos y técnicas desarrollados durante años en el campo de las ciencias de la documentación están siendo transferidos al de la informática, y su terminología reimportada como novedad indiscutida.

En el fondo, la ciencia de la información y la informática se ocupan ambas de cuestiones de propósito general relacionadas con la optimización del procesamiento "externalizado" de la información, y es lógico que todas esas cuestiones queden agrupadas en un marco teórico común. Aunque en la relación de la informática con otras disciplinas la frontera queda claramente establecida en el conocimiento específico del dominio de parte de los clientes y en el dominio de las herramientas y métodos informáticos de parte de los informáticos, esa distinción es difícil cuando ambas disciplinas se ocupan de los aspectos lógicos de la optimización de la mediación informacional.

Pero, en fin, toda cruz tiene su cara. Por una parte, la alianza de las profesiones de la información y la documentación con la informática no las ha perjudicado, antes bien ha redundado en la ampliación de sus efectivos y en un peso social mayor, que no es ajeno al prestigio que les ha proporcionado el uso intensivo de las tecnologías de la información y la comunicación. Por otra parte, los movimientos que se describen en los párrafos anteriores han venido a corregir la dirección del péndulo en el mundo de las ciencias de la documentación, moderando el énfasis tecnológico una vez que las tecnologías de la información y la comunicación han sido integradas con naturalidad y notable éxito en la práctica diaria.

Y es que, ante el avance imparable de la Computer Science y sus múltiples ramas, convertidas en la nueva coiné de las ciencias aplicadas, los investigadores y académicos en ciencias de la documentación tienen tres posibilidades, todas de gran importancia e interés y no necesariamente excluyentes. En primer lugar, pueden convertirse en tecnólogos e incorporarse a los grupos que desarrollan modelos y estándares tecnológicos para la gestión de la información, en cuyo caso - y en la práctica - se incorporan a un conjunto de disciplinas más poderosas, pero externas a las ciencias de la documentación. En segundo lugar, les cabe transformarse en puentes entre los tecnólogos y los individuos y grupos humanos y científicos que utilizan las tecnologías para comunicarse mejor y mantener su conexión con el patrimonio científico y cultural que van acumulando o por el

Scire. $11: 1$ (en.-jun. 2005) 21-26. ISSN 1135-3761. 
cual se sienten interesados, lo que les acerca a la denominada informática social o socioinformatics, pero que, sobre todo, tiene que ver con la necesidad objetiva de ir más allá de los modelos y las recetas generales para desarrollar cada campo de aplicación en sus propios términos y con respeto a sus condiciones especiales. Finalmente y en tercer lugar, pueden volver la vista a los orígenes y - asumiendo los grandes logros de la tecnología, siguiendo sus desarrollos de cerca y ocasionalmente incluso colaborando en ellos - centrarse en la función básica de las ciencias de la documentación que, en definitiva, ha sido y es la de preservar el patrimonio cultural en sus diferentes aspectos y favorecer su utilización, aprovechamiento y disfrute. En este ámbito, también interdisciplinar, pueden disfrutar de una cómoda posición equidistante de las disciplinas tecnológicas, sociales y humanas, ocupándose de lo que no pertenece al centro de interés de ninguno de los especialistas de estos campos y que, sin embargo, valoran ampliamente.

Es curioso que este estar de vuelta de la tecnología se aprecie ya también entre los técnicos y gestores, que podrían parecer enfrascados en la tarea de llevar a cabo el enorme proyecto de digitalización de la infraestructura informativa de nuestra sociedad y de afrontar los cambios que la digitalización conlleva en gestión de compras, presupuestos, personal, y los diferentes aspectos gerenciales y técnicos. Y es que, a pesar de esta urgencia, muchos de ellos están trasladando rápidamente su interés a los aspectos sociales de su profesión, una vez que sus sistemas automatizados han sido implantados y funcionan normalmente.

En cualquier caso, el movimiento inverso del péndulo va más allá de la coyuntura y responde a leyes profundas del comportamiento humano individual y social. No se debe olvidar que en la relación entre la actividad informativodocumental - ya sea esta profesional, académica o científica - y sus bases tecnológicas se producen las mismas invariantes que acontecen en cualquier relación entre fines y medios. Esto es, también respecto a lo tecnológico se aplica el principio de la primacía del fin sobre los medios, en virtud de la cual primero es necesario determinar los fines y solo entonces conviene la elección o invención de los medios.

Sin duda, la revolución tecnológica ha propiciado un énfasis en la eficacia y la eficiencia. Ha sido necesario y conveniente centrarse en poner al día los medios que se empleaban para conseguir los fines de manera mucho más limitada y costosa. Pero, conforme todo el potencial que cabía obtener de la aplicación de los nuevos medios va realizándose, el énfasis ha de volver sin remedio a los fines. Y estos, lejos de ser un asunto absolutamente cerrado, están continuamente abiertos - aun dentro de ciertas leyes - a la creación y reinterpretación individual y social.

Scire. $11: 1$ (en.-jun. 2005) 21-26. ISSN 1135-3761. 


\section{Francisco Javier García Marco}

En nuestro caso concreto de las ciencias de la documentación, este proceso no es ajeno - antes bien, está muy relacionado con él - al renovado interés por una definición que - más allá de una Information Science, que pone su énfasis en los aspectos inmediatos de la transferencia de información- defina nuestras disciplinas como ciencias aplicadas de la memoria social, dedicadas a su preservación, depuración, mejora, acceso y evaluación desde una comprensión profunda de sus razones y objetivos. En esta misión las tecnologías son fundamentales, pero el centro de la disciplina queda constituido por los esfuerzos de definición de los porqués. 